\title{
Diverse genome structures of Salmonella paratyphi C
} Wei-Qiao Liu ${ }^{\dagger 1,2}$, Gui-Rong Liu ${ }^{\dagger 1,2,3}$, Jun-Qian Li¹, Guo-Min Xu${ }^{1}$, Danni Qi ${ }^{3}$, Xiao-Yan $\mathrm{He}^{1}$, Juan Deng1, Feng-Min Zhang ${ }^{3}$, Randal N Johnston ${ }^{4}$ and ShuLin $\operatorname{Liu}^{* 1,2,3}$

\author{
Address: ${ }^{1}$ Microbiology, Peking University Health Science Center, Beijing, China, ${ }^{2}$ Microbiology and Infectious Diseases, University of Calgary, \\ Calgary, Canada, ${ }^{3}$ Microbiology, Harbin Medical University, Harbin, China and ${ }^{4}$ Biochemistry and Molecular Biology, University of Calgary, \\ Calgary, Canada \\ Email: Wei-Qiao Liu - wqliu@ucalgary.ca; Gui-Rong Liu - grliu@ucalgary.ca; Jun-Qian Li - lijunqian@263.net.cn; Guo- \\ MinXu -XGM410@163.com; Danni Qi - danni_qi@yahoo.com.cn; Xiao-Yan He - hexiaoyan1970@163.com; Juan Deng - dj5718@sina.com; \\ Feng-Min Zhang - fengminzhang@hotmail.com; Randal N Johnston - rnjohnst@ucalgary.ca; Shu-Lin Liu* - slliu@ucalgary.ca \\ * Corresponding author †Equal contributors
}

Published: 27 August 2007

BMC Genomics 2007, 8:290 doi:10.1/86/147|-2164-8-290
Received: 26 March 2007

Accepted: 27 August 2007

This article is available from: http://www.biomedcentral.com//47/-2/64/8/290

(c) 2007 Liu et al; licensee BioMed Central Ltd.

This is an Open Access article distributed under the terms of the Creative Commons Attribution License (http://creativecommons.org/licenses/by/2.0), which permits unrestricted use, distribution, and reproduction in any medium, provided the original work is properly cited.

\begin{abstract}
Background: Salmonella paratyphi C, like S. typhi, is adapted to humans and causes typhoid fever. Previously we reported different genome structures between two strains of $S$. paratyphi $C$, which suggests that $S$. paratyphi $C$ might have a plastic genome (large DNA segments being organized in different orders or orientations on the genome). As many but not all host-adapted Salmonella pathogens have large genomic insertions as well as the supposedly resultant genomic rearrangements, bacterial genome plasticity presents an extraordinary evolutionary phenomenon. Events contributing to genomic plasticity, especially large insertions, may be associated with the formation of particular Salmonella pathogens.
\end{abstract}

Results: We constructed a high resolution genome map in S. paratyphi C strain RKS4594 and located four insertions totaling $176 \mathrm{~kb}$ (including the $90 \mathrm{~kb} \mathrm{SPI7)}$ ) and seven deletions totaling 165 $\mathrm{kb}$ relative to $\mathrm{S}$. typhimurium LT2. Two rearrangements were revealed, including an inversion of $1602 \mathrm{~kb}$ covering the ter region and the translocation of the $43 \mathrm{~kb} \mathrm{l-Ceul} \mathrm{F} \mathrm{fragment.} \mathrm{The} 23$ wild type strains analyzed in this study exhibited diverse genome structures, mostly as a result of recombination between $\mathrm{rrn}$ genes. In at least two cases, the rearrangements involved recombination between genomic sites other than the rrn genes, possibly homologous genes in prophages. Two strains had a $20 \mathrm{~kb}$ deletion between $\mathrm{rrlA}$ and $r \mathrm{rlB}$, which is a highly conservative region and no deletion has been reported in this region in any other Salmonella lineages.

Conclusion: S. paratyphi $\mathrm{C}$ has diverse genome structures among different isolates, possibly as a result of large genomic insertions, e.g., SPI7. Although the Salmonella typhoid agents may not be more closely related among them than each of them to other Salmonella lineages, they may have evolved in similar ways, i.e., acquiring typhoid-associated genes followed by genome structure rearrangements. Comparison of multiple Salmonella typhoid agents at both single sequenced genome and population levels will facilitate the studies on the evolutionary process of typhoid pathogenesis, especially the identification of typhoid-associated genes. 


\section{Background}

Of the over 2500 Salmonella serotypes recognized to date [1], about 1400 infect humans and other warm-blooded vertebrates, which are classified into Salmonella subgroup I (now often referred to as Salmonella enterica subspecies enterica [2-4]). Although most of these Salmonella serotypes cause self-limiting gastroenteritis in humans, four cause typhoid fever, a serious and potentially fatal systemic infection, including $S$. typhi (see a recent review [5]) and $S$. paratyphi A, B and C. It is a long unanswered question whether different Salmonella typhoid agents cause the disease by similar or distinct mechanisms. As all Salmonella share high levels of genetic similarity, it is possible to reveal genetic differences or similarities in pathogenicity among the Salmonella typhoid agents by focusing on genomic features common to some or all of the Salmonella typhoid agents.

The extraordinary levels of genetic similarity among salmonellae were recognized first by genomic DNA re-association experiments [6], later by physical mapping $[7,8]$, and recently by whole genome sequencing [9-13]. In the mid-1990s, physical mapping revealed an overall common genome structure among all Salmonella; it also revealed special features of individual Salmonella lineages, such as the major genomic insertions and rearrangements of S. typhi [14-16] and S. paratyphi A [17], which were later all confirmed by whole genome sequencing $[9,11,12]$. Sequence comparison of the Salmonella genomes further reveals that about $13 \%$ of the genes in $S$. typhi are not found in S. typhimurium $[9,10]$, and many of these serovar-specific genes were apparently acquired by lateral transfer of large DNA segments from other sources [18], which, if $12 \mathrm{~kb}$ or larger, can be resolved on the physical maps $[14,17,19-22]$.

Several lines of evidence suggest that the typhoid agents have not evolved by vertical descent of one from another, as genetic distances are not closer among the typhoid agents than each of them to the non-typhoidal salmonellae $[12,23-25]$. However, they may have common or similar routes of acquisition of genes coding for the typhoid pathogenicity. Comparison of multiple typhoid agents may lead to identification of these genes.

S. paratyphi C is a member of serogroup C1 [2], causing typhoid in humans but, unlike $S$. typhi, also occasionally infecting animals [26]. Previously we reported I-CeuI maps on two S. paratyphi C strains, RKS4587 and RKS4594, which are very different in size and organization of the seven I-CeuI fragments. In several ways, $S$. paratyphi C is similar to $S$. typhi, including the possession of a large pathogenicity island, SPI7, with genes coding for the $\mathrm{Vi}$ (virulence) antigen and other genes potentially associated with virulence $[9,14,15,27-29]$. It is thus of great sig- nificance to reveal the genomic features of $S$. paratyphi C at higher resolution and involving a broader range of wild type strains, and then compare them with those of $S$. typhi to explore the evolution of the typhoid-associated pathogenicity. In this paper, we first report a high resolution genome map of a representative $S$. paratyphi $\mathrm{C}$ strain, RKS4594, featured with several insertions, deletions and rearrangements. We then present genome maps of additional wild type strains of $S$. paratyphi $\mathrm{C}$ constructed with I-CeuI, which reveal diverse genome structures among the wild type strains of $S$. paratyphi $C$. Some strains have deletions in the highly conserved metE-argE region, which have not previously been observed in any other Salmonella strains.

\section{Results \\ Cleavage of S. paratyphi C RKS4594 genomic DNA with I- Ceul}

I-CeuI is an intron-encoded endonuclease, with cleavage sites in $r r l$ genes [7,30-33]. Cleavage of $S$. paratyphi C RKS4594 genomic DNA with I-Ceul generated seven fragments (Figure 1). This number is consistent with the previously analyzed Salmonella genomes [8], as all Salmonella lineages have seven $\mathrm{rrl}$ genes.

In Figure 1A, there are bright as well as less bright DNA bands, the latter being labeled as combinations of two or three of the seven bright bands. These less bright DNA bands are partial cleavage products showing the neighboring relationships of the seven I-CeuI cleaved DNA segments. Analyses of both complete and partial I-CeuI cleavages resulted in the cleavage map of $S$. paratyphi C RKS4594 in Figure 1B. In designation of the I-CeuI fragments, the same letters were used to label homologous DNA segments in different Salmonella lineages. In S. typhimurium LT2, the order of the seven I-CeuI fragments is ABCDEFG clockwise, but in S. paratyphi C RKS4594 the order is ABCFDEG due to the translocation of fragment $F$. Translocations of I-CeuI fragments are usually mediated by homologous recombination between pairs of the $\mathrm{rrn}$ genes $[15,16,34,35]$, which usually have greater than $99 \%$ sequence identity. The translocation of I-CeuI F in S. paratyphi C RKS4594 led to three hybrid rrn operons. The $\mathrm{rrl}$ genes are used to exemplify the hybrid $r r n$ operons in Figure $1 \mathrm{~B}$, shown as $\mathrm{rrlC} / \mathrm{B}, \mathrm{rrlE} / \mathrm{C}$ and $\mathrm{rrlB} / \mathrm{E}$, but recombination may also occur in $r r s$.

\section{Xbal and Avrll cleavages and transposon Tn 10 insertion analysis of the genome}

XbaI cleavage generated 23 fragments, ranging from 684 $\mathrm{kb}$ (band $\mathrm{A}$ in Figure $2 \mathrm{~A}$ ) to $3 \mathrm{~kb}$ (band $\mathrm{W}$, run out of the gel in Figure 2A but seen on other gels). AvrII cleavage generated 26 fragments, ranging from $866 \mathrm{~kb}$ (band $\mathrm{A}$ in Figure $2 \mathrm{~B}$ ) to $11 \mathrm{~kb}$ (band $\mathrm{Z}$, run out of the gel in Figure $2 \mathrm{~B})$. To determine the order of fragments in both XbaI and 


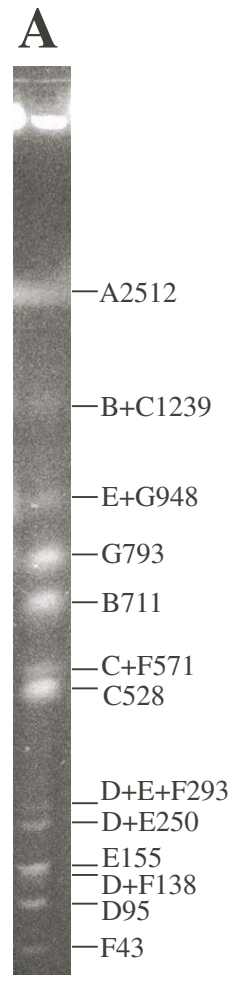

B

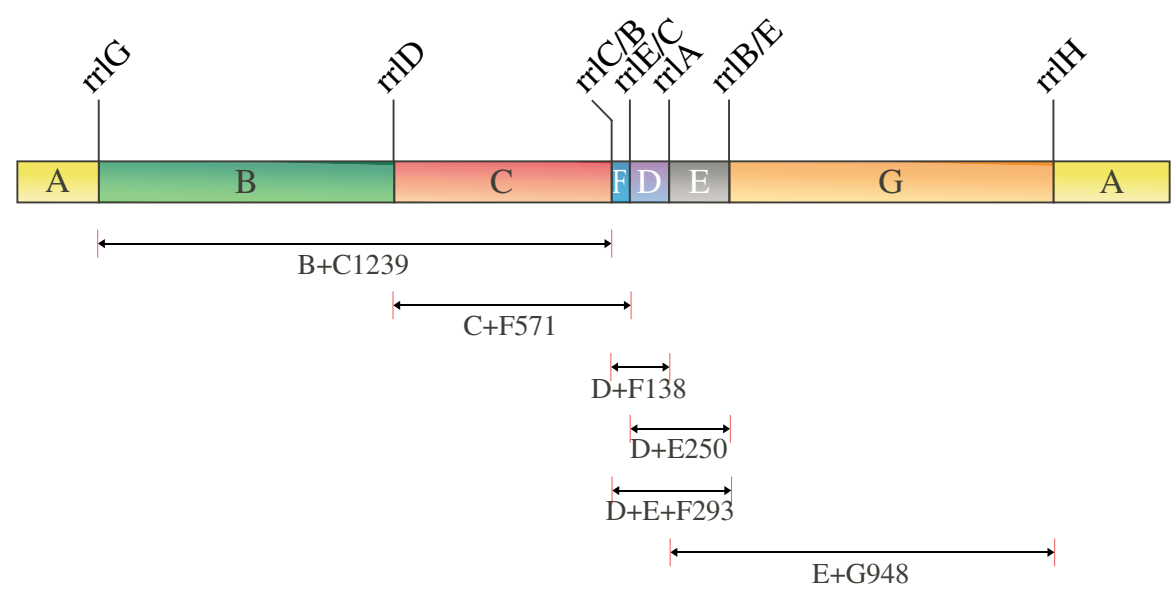

\section{Figure I}

I-Ceul mapping of S. paratyphi C RKS4594. (A) PFGE separation of I-Ceul cleaved genomic DNA. See more detailed description in the text about complete and partial cleavages of the genomic DNA with I-Ceul. (B) I-Ceul cleavage map of the RKS4594 genome based on (A). The genome is circular; here it is shown as a linear map for the convenience of illustrating the mapping procedure. Only parts of fragment $A(2512 \mathrm{~kb})$ are shown at the ends of the linear map. The remaining 6 fragments are drawn to scale.

AvrII cleavages and locate genes on the genome of $S$. paratyphi $\mathrm{C}$, we transferred the transposon Tn10 that was inserted in known genes in S. typhimurium LT2 [36] to the S. paratyphi C background by bacteriophage P22 mediated transduction as previously described [19], but with the introduction of $\mathrm{O} 12$ antigen-encoding genes to make $S$. paratyphi C sensitive to P22 (details provided in Materials and Methods). Since the Tn10 sequence contains both $\mathrm{XbaI}$ and AvrII cleavage sites [37], the location of a Tn10 insertion can be determined by XbaI or AvrII cleavage and PFGE analyses. DNA from a strain with a Tn10 insertion in a specific fragment will lose that fragment, and two fragments will be detected that sum to the size of the lost fragment plus $9.3 \mathrm{~kb}$, which is the size of Tn10. We determined locations for 66 genes, as shown in Figure 3.
A high resolution genome map of S. paratyphi C RKS4594 After summarizing experimental results obtained by cleavages with I-CeuI, XbaI and AvrII, Tn10 insertion analyses and double digestions (technical details described previously [36]), we constructed a high resolution genome map for S. paratyphi C RKS4594 (Figure 3). XbaI fragment $\mathrm{P}$ (55 kb) was not mapped on the chromosome; it is a plasmid (pSPC on Figure 2A and 2B) with a copy number of 3 to 5 as judged by brightness of the DNA band when compared with other bands on a PFGE gel. In addition to an XbaI cleavage site, this plasmid also has an AvrII site (See Figure 2B; the plasmid band migrates together with the $60 \mathrm{~kb}$ AvrII fragment Q). Most genes are in the same order as in S. typhimurium LT2, with the following exceptions. The translocation of I-Ceul fragment F moves 

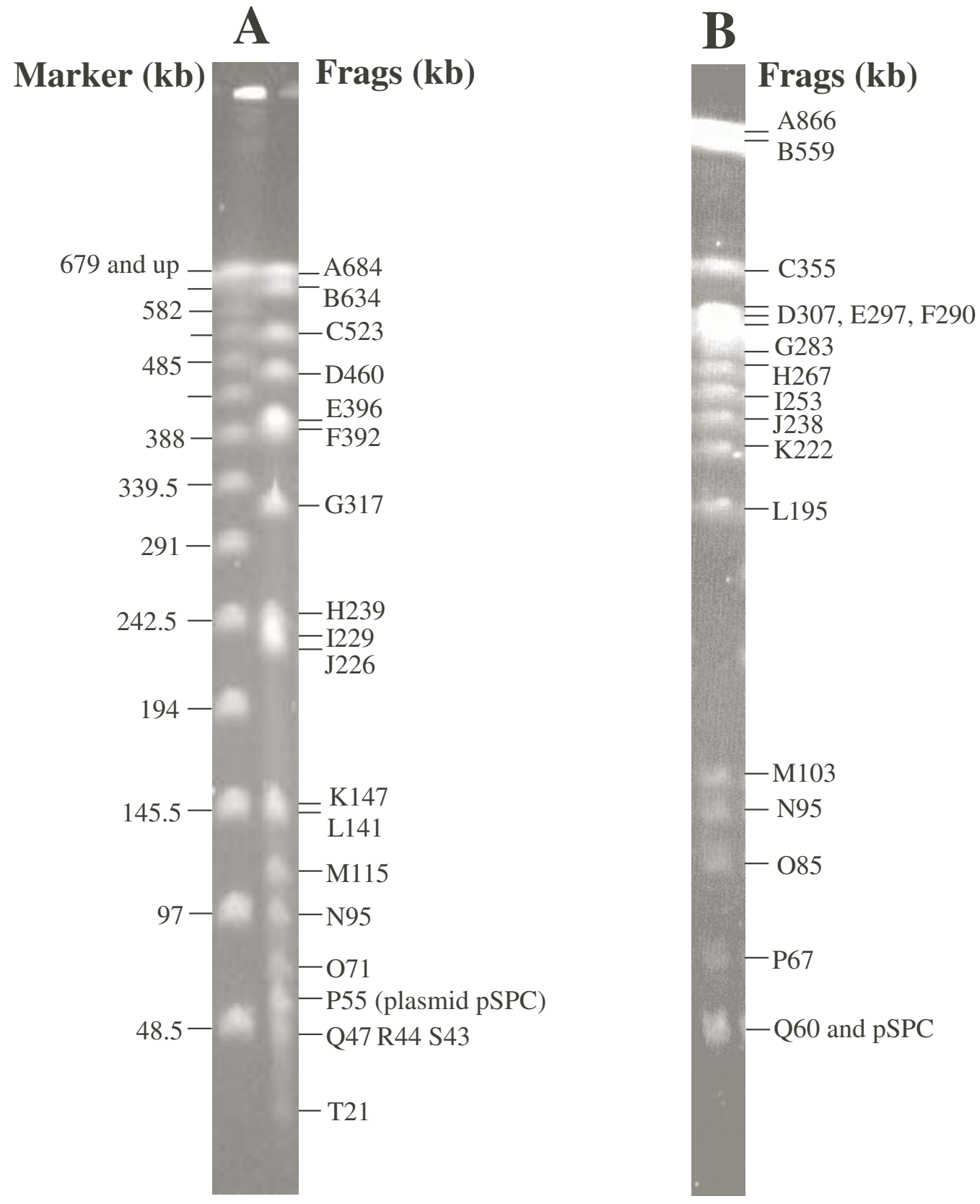

Figure 2

PFGE separation of cleaved genomic DNA of S. paratyphi C RKS4594. (A), cleavage with Xbal; (B), cleavage with Avrll. 


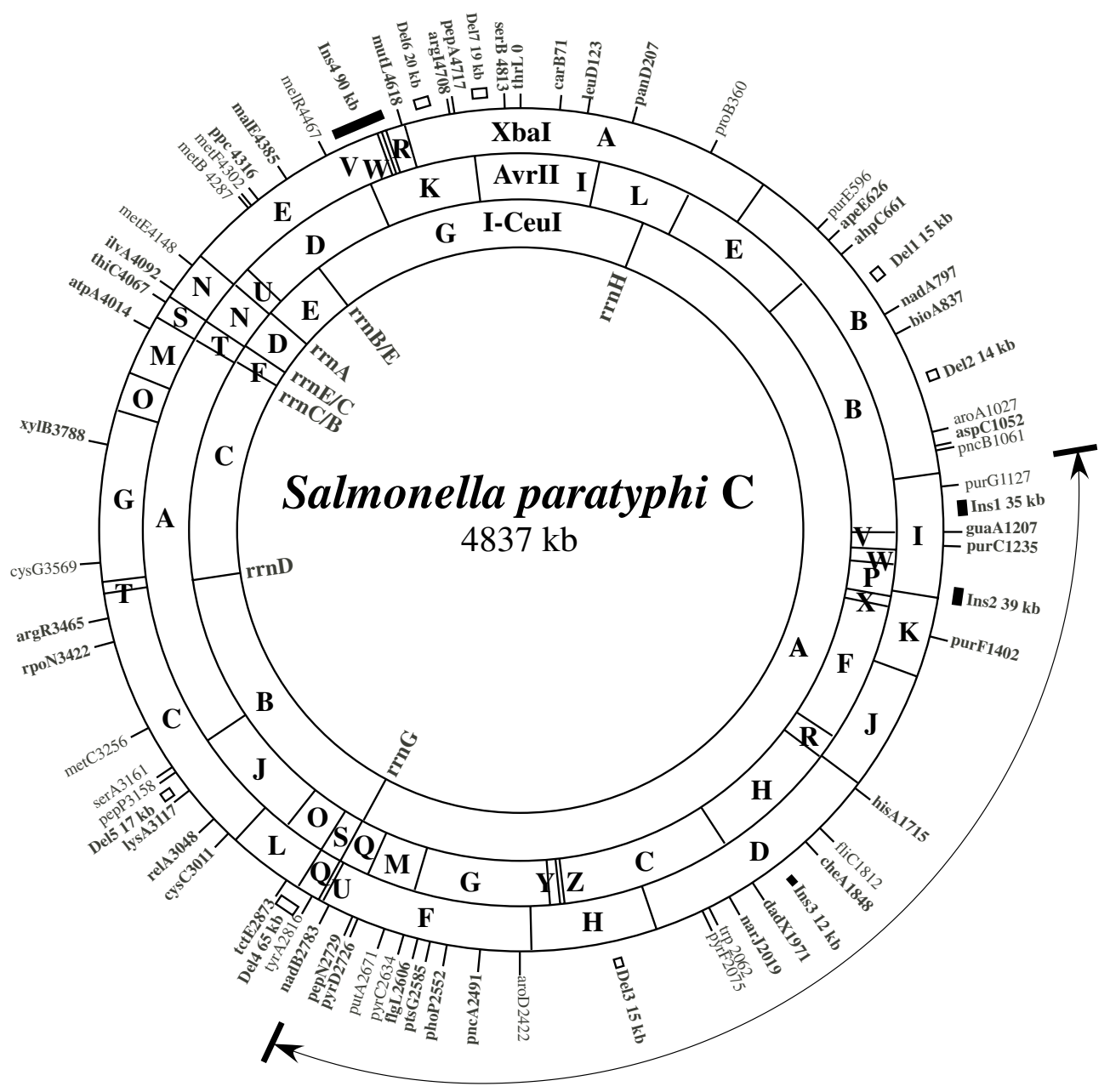

Figure 3

Genome map of S. paratyphi C RKS4594. The sizes of cleavage fragments on the map are shown to scale, and are listed in Figs I and 2. Solid rectangles indicate insertions (Ins I-4) and open rectangles indicate deletions (DelI-7), numbered clockwise, relative to S. typhimurium LT2; the sizes are roughly to scale. The gene thrL is taken as the beginning of the map for the convenience of comparison with other Salmonella maps. The double-headed arrow, with one end being between pncB (at I06I kb) and purG (at II $27 \mathrm{~kb}$ ) and the other between pepN (at $2729 \mathrm{~kb}$ ) and nadB (at $2783 \mathrm{~kb}$ ), covers the region of inversion with respect to the chromosome of S. typhimurium LT2.

the thiC gene (and all other genes between $r r n B$ and $r r n E$, data not shown here) to a new location; a very large inversion (estimated as $1602 \mathrm{~kb}$ ) includes purG (at $1127 \mathrm{~kb}$ on the map) and pepN (at $2729 \mathrm{~kb}$ on the map). On the genome of $S$. typhimurium LT2, the region clockwise to pncB (which, at $1061 \mathrm{~kb}$ in $S$. paratyphi C, is just outside the inverted region) is occupied by prophage Gifsy-2 (45 $\mathrm{kb}$ in size), and the region counterclockwise to nadB (which, at $2783 \mathrm{~kb}$ in $S$. paratyphi $\mathrm{C}$, is just outside the inverted region at the other end of the $1602 \mathrm{~kb}$ inversion) is occupied by prophage Gifsy-1 (48 kb). The distance between $p n c B$ and purG (66 kb) plus that between pepN and $n a d B(54 \mathrm{~kb})$ in $S$. paratyphi C RKS4594 (total $120 \mathrm{~kb}$ ) roughly equals the distance between $p n c B$ and $p e p N$ (47 $\mathrm{kb})$ plus that between purG and $\operatorname{nadB}(72 \mathrm{~kb})$ in $S$. typhimurium LT2 (total $119 \mathrm{~kb}$ ). So, judged by the distances between genes, it seems that two prophages with sizes similar to those of Gifsy-2 and Gifsy-1 are present in $S$. paratyphi C RKS4594, although their identities are unknown. Because the inversion seems to include most 
genes of the two prophages, and because the prophages are inverted in orientation in S. typhimurium LT2, we speculate that the exchange points of the inversion were between genes in the two prophages. At the position of Gifsy-2 in S. typhimurium LT2, S. typhi CT18 has a different phage sequence, but at the position of Gifsy-1 in $S$. typhimurium LT2, S. typhi CT18 does not have a phage sequence $[9,10]$. A similar inversion has not been observed in other Salmonella serovars.

There are several genomic regions with increased distances between genes relative to $S$. typhimurium LT2, which we speculate to be DNA segments acquired from foreign sources during the evolution of $S$. paratyphi C. The first (Ins1) is $35 \mathrm{~kb}$ between purG and guaA, and the second (Ins2) is $39 \mathrm{~kb}$ between purC and purF. It is possible that both are prophages as judged by their sizes, or that one or both might be summations of smaller insertions in those regions from different sources. A $12 \mathrm{~kb}$ genomic increase (Ins3) was located in the region between cheA and $d a d X$. In this region, there is a $50 \mathrm{~kb}$ phage-associated DNA segment in S. typhi CT18 but not in S. typhimurium LT2 $[9,10]$. It is not known whether the $12 \mathrm{~kb}$ is part of the $50 \mathrm{~kb}$ phage DNA or whether the whole $50 \mathrm{~kb}$ phage DNA is here and there is a $38 \mathrm{~kb}$ deletion, collectively giving rise to a net $12 \mathrm{~kb}$ increase of DNA in that region.

The largest insertion is the one between melR and mutL, about $90 \mathrm{~kb}$, in a location similar to that of SPI7 in S. typhi $[9,14,15]$. As it is previously known that the genome of $S$. paratyphi C carries a shorter version of SPI7 [29], we assume that this $90 \mathrm{~kb}$ insertion probably is the $S$. paratyphi C version of SPI7.

We also located genomic regions of reduced distances (possible deletions) between genes in S. paratyphi C RKS4594 when compared with S. typhimurium LT2. Starting from the gene thr and moving clockwise, the first possible deletion is one about $15 \mathrm{~kb}$ between $a h p C$ and nadA and the second one is about $14 \mathrm{~kb}$ between bioA and aroA. Whether they contain single deletions or several smaller deletions would both be interesting, especially regarding the gene loss involved, as the absence of some of the genes may be associated with host restriction.

The distance between aroD and $p y r F$ is $362 \mathrm{~kb}$ in $S$. typhimurium LT2 but only $347 \mathrm{~kb}$ in S. paratyphi C RKS4594. In the same region on the genome of $S$. typhi CT18, there is a $34 \mathrm{~kb}$ phage-associated DNA sequence. Depending on whether $S$. paratyphi C RKS4594 contains this $34 \mathrm{~kb}$ phage DNA, this organism has a deletion of $15 \mathrm{~kb}$ or $49 \mathrm{~kb}$ in this region relative to $S$. typhimurium LT2.

S. typhimurium LT2 has prophage Fels-2 (35 kb) between genes tyrA and tctE. In this region, S. paratyphi C RKS4594 is $65 \mathrm{~kb}$ shorter compared to $S$. typhimurium LT2. If Fels-2 is not present, there should be another $30 \mathrm{~kb}$ deletion in S. paratyphi C RKS4594. Three additional regions of possible deletions of $17 \mathrm{~kb}$ (between $l y s A$ and pepP), $20 \mathrm{~kb}$ (between mutL and $\operatorname{argI}$ ) and $19 \mathrm{~kb}$ (between pepP and serB) need further characterization. Although we do not completely rule out the possibility that the reduced distances between genes actually resulted from translocation of DNA segments instead of deletions, it is very unlikely, as gene order is highly conserved in Salmonella and DNA translocation does not generally occur except those mediated by recombination of $r r n$ genes or other repeated elements.

\section{Plastic genome structure of S. paratyphi C}

To determine whether the genome structure of $S$. paratyphi $\mathrm{C}$ is uniform and stable among the populations like that of $S$. paratyphi A [17], or is diverse and plastic like that of $S$. typhi $[15,16,35]$, we made I-CeuI maps on $S$. paratyphi $\mathrm{C}$ isolates gathered from different geographical areas over a broad range of time. As shown in Figure $4 \mathrm{~A}$, individual S. paratyphi C strains have obviously different PFGE patterns, especially regarding the partial cleavage bands, which reflect different orders of the genomic DNA segments (Figure 4B).

Rather strikingly, two strains, RKS4589 and RKS4590, have a $20 \mathrm{~kb}$ deletion in a region between $\mathrm{rrlA}$ and $\mathrm{rrlB}$. This region is extremely stable in Salmonella and no deletion has been reported in other Salmonella lineages. Currently, we do not know what genes have been deleted in these two strains and whether they have identical deletions.

\section{Discussion}

The existence of different typhoid agents causing very similar clinical manifestations presents exceptional opportunities for elucidating their origin(s) and for understanding the molecular mechanisms of host adaptability. Two of the four human typhoid agents, S. typhi and S. paratyphi A, have been studied at the level of physical genome maps with a focus on genome structure in large numbers of isolates [14-17,35] and at the level of whole genome sequence with a focus on individual genes and their regulation in representative strains $[9,11,12]$. When compared with $S$. typhimurium, S. typhi has over 600 unique genes [9]. It is reasonable to speculate that some of the S. typhispecific genes may be directly involved in typhoid pathogenicity, although cooperation with genes of the "core Salmonella genome", i.e., genes shared by most Salmonella lineages, should also be important. If one assumes that the typhoid agents share some or many typhoid-associated genes, then comparisons among them should help in identification. Comparative studies between $S$. typhi and S. paratyphi A, however, are so far not conclusive, because 


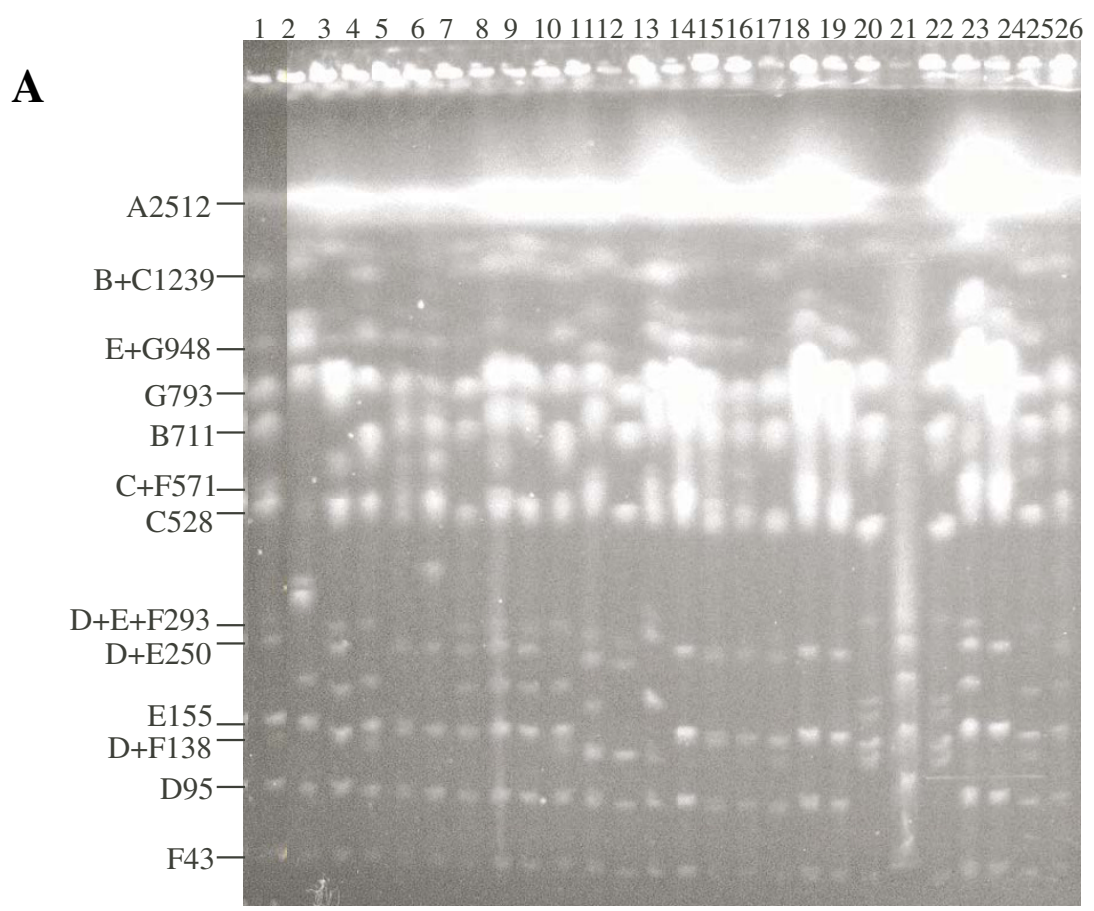

B

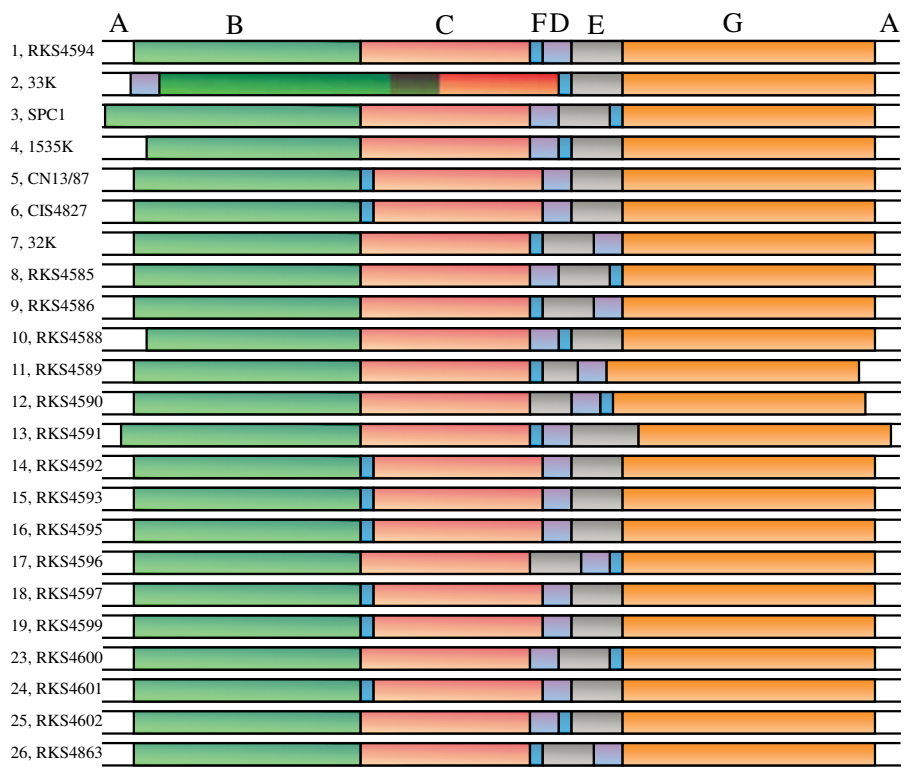

\section{Figure 4}

Diversity in genome structure among wild type strains of S. paratyphi C. (A) PFGE patterns of I-Ceul cleaved genomic DNA from wild type strains of S. paratyphi C. Lanes: I, RKS4594 (IP2/88); 2, RKS4587 (33K); 3, SPCI; 4, I535K; 5 , CNI 3/87; 6, CIS4827; 7, 32K; 8, RKS4585; 9, RKS4586; I0, RKS4588; II, RKS4589; I2, RKS4590; I3, RKS459I; I4, RKS4592; I5, RKS4593; 16, RKS4595; I7, RKS4596; I8, RKS4597; 19, RKS4599; 20, S. typhi Ty2 (for comparison); 2I, $\lambda$ DNA concatemer as size marker; 22, S. typhi Ty2; 23, RKS4600; 24, RKS460I; 25, RKS4602; 26, SA4863. (B) I-Ceul maps of S. paratyphi C wild type strains based on data from (A). 
they each have many genomic features not shared by the other. Therefore, it is necessary to compare more than two Salmonella typhoidal lineages to further highlight some possible common genomic features. Additionally, it is also possible that some typhoid agents may have evolved vertically from a common ancestor and others may have acquired typhoid pathogenicity horizontally. Systematic genome comparisons among multiple typhoid agents are rational approaches toward elucidating these evolutionary processes.

The main purpose of this study was to reveal large scale genomic features of a representative $S$. paratyphi C strain and overall genome structure of $S$. paratyphi C populations. On the high resolution physical map of $S$. paratyphi C RKS4594, we resolved four possible genomic insertions, totaling $176 \mathrm{~kb}$, and seven possible deletions, totaling $165 \mathrm{~kb}$, relative to $S$. typhimurium LT2. At this stage, we do not know what genes are contained in the insertions and what genes are involved and deletions, but localization of these insertions and deletions on the genome will significantly facilitate comparative studies among the typhoid agents.

A basic feature of the genome structure of $S$. paratyphi $\mathrm{C}$ is its plasticity - large genomic DNA segments are arranged differently in different wild type strains. In strain RKS4594, we first revealed two rearrangement events, including inversion of a $1602 \mathrm{~kb}$ segment covering the ter region and the translocation of the $43 \mathrm{~kb}$ I-CeuI $\mathrm{F}$ fragment from its location between I-CeuI E and G as in $S$. typhimurium and most other Salmonella genomes to the location between I-CeuI C and D, leading to the order ICeuI ABCFDEG in $S$. paratyphi C (Figure 3). Diverse genome structures among the $S$. paratyphi $\mathrm{C}$ wild type strains representing different populations have resulted from homologous recombination between $r$ genes in all analyzed strains except RKS4587, in which a very rare inversion occurred between a site in I-Ceul fragment B and a site in I-CeuI fragment $\mathrm{C}$; we are now determining the exact locations and identities of the exchange end points (Liu, on-going project).

The previously analyzed typhoid agents have different situations regarding the stability of genome structure. We first reported the rearranged genome structure of $S$. typhi Ty2 $[14,15]$ and then found that wild type strains of $S$. typhi representing different populations have diverse genome structures; we called this phenomenon "genomic plasticity" $[16,34]$. Our interpretation of this phenomenon is that large insertions disrupt the physical balance of the genome between ori and ter, and rearrangements will rebalance the genome [35]. In contrast, the other extensively investigated typhoid agent, $S$. paratyphi $\mathrm{A}$, at both physical map and sequence levels, has a uniform genome structure among different isolates, even though this organism does have insertions totaling $100 \mathrm{~kb}$ clustered together on the genome. Interestingly, the $2400 \mathrm{~kb}$ inversion, seen in all examined wild type strains of $S$. paratyphi A, nearly completely restored the genomic balance [17], making it unnecessary for the bacteria to further rearrange the genome. The situation with $S$. paratyphi $\mathrm{B}$, on the other hand, seems much more complex, because, unlike $S$. typhi, S. paratyphi A or S. paratyphi C, which are all monophyletic $[4,14,15,23]$, bacteria under the name $S$. paratyphi $\mathrm{B}$ seem to be genetically diverse. For example, the d-tartrate-positive subline (strains that ferment $\mathrm{d}$-tartrate) causes gastroenteritis instead of typhoid. Kauffmann proposed the name $S$. java for this subline [38], however Le Minor et al. proposed that the name $S$. java be dropped [39]. Even within the d-tartrate-negative and typhoidcausing subline, the diversity in genome structure, as reflected by XbaI and AvrII cleavage patterns, is also significant [20]. Genome sequencing of a representative typhoid-causing strain(s) of $S$. paratyphi B followed by population analysis will provide insights into the phylogenetics and evolution of $S$. paratyphi $\mathrm{B}$ as a typhoid agent.

This study demonstrates that $S$. paratyphi $\mathrm{C}$ is similar to $S$. typhi in the plasticity of genome structure. However, such a similarity is not indicative of their relatedness. Instead, this similarity suggests a similar route of evolution: acquisition of typhoid causing genes, disruption of physical balance of the genome, and rearrangement of the genome to restore the balance. This route may apply to $S$. paratyphi $\mathrm{A}$ as well: the non-plastic feature of its genome may be merely a result of the near complete restoration of the genome balance by the $2400 \mathrm{~kb}$ inversion. It is not known at present whether $S$. paratyphi B, monophyletic or polyphyletic as it may turn out to be, has a stable or plastic genome structure; however, it may too have followed a similar route of pathogenic evolution. Revelation of genes that contribute to the typhoid pathogenesis in the individual typhoid agents will update our knowledge on pathogenically similar but phylogenetically not directly related bacteria. For achieving this goal, sequencing of additional Salmonella typhoid agents is currently underway in several institutions, and some of the sequencing projects are close to or already at the finishing stages.

This study also revealed an unusual feature of $S$. paratyphi C: unlike S. typhi wild type strains that do not have significant DNA content differences except SPI7 that is missing from some $S$. typhi isolates [27], two $S$. paratyphi C strains in this study have $20 \mathrm{~kb}$ deletions in a normally extremely stable genomic region between $\mathrm{rrlA}$ and $\mathrm{rrlB}$ (Figure 4). This finding suggests that genes in the deleted $20 \mathrm{~kb}$ DNA are no longer needed at least in some S. paratyphi C strains, or they are not needed by any of the typhoid agents in general. It is possible that, considering the short 
evolutionary history of the Salmonella typhoid agents $[40,41]$, these bacteria may have not yet eliminated all of the non-selected genes, although some stochastic factors, such as integration or excision of prophages that make genomic rebalancing necessary, may have worked to help streamline the genome by removing some of the presumably unneeded genes before they even had a chance to become pseudogenes. These findings may help prioritize genes for functional analyses by excluding large numbers of genes from further study.

\section{Conclusion}

S. paratyphi C has diverse genome structures, possibly as a result of large genomic insertions, e.g., SPI7. Although the Salmonella typhoid agents may not be more closely related among them than each of them to other Salmonella lineages, they may have evolved in similar ways, i.e., acquiring typhoid-associated genes and making genome structure rearrangements. Comparison of multiple Salmonella typhoid agents at both single sequenced genome and population levels will facilitate the studies on the evolutionary process of typhoid pathogenesis, especially the identification of typhoid-associated genes.

\section{Methods}

\section{Bacterial strains}

The following $23 \mathrm{~S}$. paratyphi $\mathrm{C}$ strains were used in this study: RKS4594 (IP2/88), RKS4587 (33K), SPC1, 1535K, CN13/87, CIS4827, 32K, RKS4585, RKS4586, RKS4588, RKS4589, RKS4590, RKS4591, RKS4592, RKS4593, RKS4595， RKS4596， RKS4597， RKS4599， RKS4600, RKS4601, RKS4602, and SA4863; information on these strains can be found at the Salmonella Genetic Stock Center. Culture conditions were as described previously [36].

\section{Isolation, endonuclease cleavage, and electrophoretic separation of bacterial genomic DNA}

Bacteria were embedded in agarose to avoid shearing of genomic DNA during isolation, as described previously [21]. Endonuclease cleavage with I-CeuI, XbaI and AvrII and separation of the cleavage fragments by pulsed field gel electrophoresis (PFGE) were also described previously $[7,14]$.

\section{Transfer of Tn 10 insertions through bacteriophage P22 mediated transduction}

A large number of Tn10 insertions into genes with known functions have been established in S. typhimurium LT2 in a great range of laboratories. We transferred Tn10 insertions from $S$. typhimurium LT2 to $S$. paratyphi C by bacteriophage P22 mediated transduction to locate these genes through homologous recombination. As P22 infects only Salmonella serovars that express $\mathrm{O} 12$ antigen but $S$. paratyphi $\mathrm{C}$ does not have $\mathrm{O} 12$, we transferred the cosmid
pPR1347 [42] carrying the genes coding for the long chain $\mathrm{O}$ antigen into $S$. paratyphi C RKS4594 to make it sensitive to P22. The P22 transduction experiments have been described previously [19]. Briefly, we made P22 lysates from a selected set of Tn10 insertion mutants of $S$. typhimurium LT2 by growing a $3 \mathrm{ml}$ overnight culture in LB broth of these selected Tn10 mutants and inoculating these cultures with phage P22 at a multiplicity of infection of 1:100, followed by co-incubation for 6 hours. After removal of the cell debris by centrifugation, the lysates, which contained approximately $10^{11} \mathrm{pfu} / \mathrm{ml}$ of phage particles, were ready for use in the transduction. For transferring the Tn10 insertions to $S$. paratyphi $\mathrm{C}$, we spread 100 $\mu$ l overnight culture of $S$. paratyphi C carrying pPR1347 and $10 \mu \mathrm{l}$ lysate onto an LB plate containing tetracycline. A colony was picked up and re-streaked on another tetracycline plate for single colony isolation. One colony from the second tetracycline plate was used for phenotype tests and mapping.

\section{Enzymes and chemicals}

I-CeuI, AvrII and SpeI were purchased from New England BioLabs; XbaI and proteinase $\mathrm{K}$ were from Roche. Most other chemicals were from the Sigma Chemical Co.

\section{Authors' contributions}

GRL and DQ initiated the PFGE experiments; WQL, GRL and JQL completed the physical mapping; $\mathrm{XYH}$, JD, GMX, LW and FMZ were involved in construction of a P22 sensitive strain of RKS4594 by introducing into the bacteria the cosmid pPR1347 that carries O12 encoding genes, bacterial culture, Tn10 insertion inactivation, DNA isolation, and phenotype testing; RNJ and SLL coordinated the work; WQL and SLL produced the manuscript.

\section{Acknowledgements}

We thank Drs. K. E. Sanderson, R. K. Selander, T. Pang and M. Y. Popoff for providing us with the $S$. paratyphi $C$ strains. WQL was a visiting student to Peking University Health Science Center, Beijing, China.

This work was supported by a CIHR grant to RNJ; and a grant from National Natural Science Foundation of China (NSFC number: 30370774), a 985 Project grant of Peking University Health Science Center, a Specialized Research Fund for the Doctoral Program of Higher Education (No. 2003000 1029), and a Discovery Grant from NSERC to SLL.

\section{References}

I. Popoff MY, Bockemuhl J, Gheesling LL: Supplement 2002 (no. 46) to the Kauffmann-White scheme. Res Microbiol 2004, I 55:568-570.

2. Popoff MY, Le Minor LE: Genus XXXIII. Salmonella. In Bergey's Mannual of Systematic Bacteriology Volume 2. 2nd edition. Edited by: Brenner DJ, Krieg NR and Stanley JT. , Springer; 2005:764-799.

3. Le Minor L, Popoff MY: Designation of Salmonella enterica sp. nov., nom. rev., as the type and only species of the genus Salmonella. International Journal of Systematic Bacteriology 1987, 37:465-468.

4. Reeves MW, Evins GM, Heiba AA, Plikaytis BD, Farmer JJ 3rd: Clonal nature of Salmonella typhi and its genetic relatedness to other salmonellae as shown by multilocus enzyme electro- 
phoresis, and proposal of Salmonella bongori comb. nov. J Clin Microbiol 1989, 27:3।3-320.

5. Parry CM, Hien TT, Dougan G, White NJ, Farrar J]: Typhoid fever. N Engl J Med 2002, 347: 1770- I782.

6. Crosa JH, Brenner DJ, Ewing WH, Falkow S: Molecular relationships among the Salmonelleae. I Bacteriol I 973, I I 5:307-3 I5.

7. Liu SL, Hessel A, Sanderson KE: Genomic mapping with I-Ceu I, an intron-encoded endonuclease specific for genes for ribosomal RNA, in Salmonella spp., Escherichia coli, and other bacteria. Proc Natl Acad Sci U S A 1993, 90:6874-6878.

8. Liu SL, Schryvers AB, Sanderson KE, Johnston RN: Bacterial phylogenetic clusters revealed by genome structure. I Bacteriol 1999, 181:6747-6755.

9. Parkhill J, Dougan G, James KD, Thomson NR, Pickard D, Wain J, Churcher C, Mungall KL, Bentley SD, Holden MT, Sebaihia M, Baker $\mathrm{S}$, Basham D, Brooks K, Chillingworth T, Connerton P, Cronin A, Davis P, Davies RM, Dowd L, White N, Farrar J, Feltwell T, Hamlin N, Haque A, Hien TT, Holroyd S, Jagels K, Krogh A, Larsen TS, Leather S, Moule S, O'Gaora P, Parry C, Quail M, Rutherford K, Simmonds M, Skelton J, Stevens K, Whitehead S, Barrell BG: Complete genome sequence of a multiple drug resistant Salmonella enterica serovar Typhi CT I 8. Nature 200I, 4I 3:848-852.

10. McClelland M, Sanderson KE, Spieth J, Clifton SW, Latreille P, Courtney L, Porwollik S, Ali J, Dante M, Du F, Hou S, Layman D, Leonard S, Nguyen C, Scott K, Holmes A, Grewal N, Mulvaney E, Ryan E, Sun H, Florea L, Miller W, Stoneking T, Nhan M, Waterston R, Wilson RK: Complete genome sequence of Salmonella enterica serovar Typhimurium LT2. Nature 200 I, 4/3(6858):852-856.

II. Deng W, Liou SR, Plunkett G 3rd, Mayhew GF, Rose DJ, Burland V, Kodoyianni V, Schwartz DC, Blattner FR: Comparative genomics of Salmonella enterica serovar Typhi strains Ty2 and CTI8. J Bacteriol 2003, 185:2330-2337.

12. McClelland M, Sanderson KE, Clifton SW, Latreille P, Porwollik S, Sabo A, Meyer R, Bieri T, Ozersky P, McLellan M, Harkins CR, Wang C, Nguyen C, Berghoff A, Elliott G, Kohlberg S, Strong C, Du F, Carter J, Kremizki C, Layman D, Leonard S, Sun H, Fulton L, Nash W, Miner T, Minx P, Delehaunty K, Fronick C, Magrini V, Nhan M, Warren W, Florea L, Spieth J, Wilson RK: Comparison of genome degradation in Paratyphi A and Typhi, human-restricted serovars of Salmonella enterica that cause typhoid. Nat Genet 2004, 36: I268-1274.

13. Chiu CH, Tang P, Chu C, Hu S, Bao Q, Yu J, Chou YY, Wang HS, Lee YS: The genome sequence of Salmonella enterica serovar Choleraesuis, a highly invasive and resistant zoonotic pathogen. Nucleic Acids Res 2005, 33:1690-1698.

14. Liu SL, Sanderson KE: Genomic cleavage map of Salmonella typhi Ty2. J Bacteriol 1995, 177:5099-5107.

15. Liu SL, Sanderson KE: Rearrangements in the genome of the bacterium Salmonella typhi. Proc Natl Acad Sci U S A 1995, 92:1018-1022.

16. Liu SL, Sanderson KE: Highly plastic chromosomal organization in Salmonella typhi. Proc Natl Acad Sci U S A 1996, 93: $10303-10308$.

17. Liu SL, Sanderson KE: The chromosome of Salmonella paratyphi $A$ is inverted by recombination between $\mathrm{rrnH}$ and rrnG. I Bacteriol 1995, I77:6585-6592.

18. Porwollik S, McClelland M: Lateral gene transfer in Salmonella. Microbes Infect 2003, 5:977-989.

19. Liu SL, Hessel A, Sanderson KE: The Xbal-BInl-Ceul genomic cleavage map of Salmonella enteritidis shows an inversion relative to Salmonella typhimurium LT2. Mol Microbiol 1993, 10:655-664.

20. Liu SL, Hessel A, Cheng HY, Sanderson KE: The Xbal-BInl-Ceul genomic cleavage map of Salmonella paratyphi B. J Bacteriol 1994, 176: 1014-1024.

21. Liu GR, Rahn A, Liu WQ, Sanderson KE, Johnston RN, Liu SL: The evolving genome of Salmonella enterica serovar Pullorum. J Bacteriol 2002, 184:2626-2633.

22. Wu KY, Liu GR, Liu WQ, Wang AQ, Zhan S, Sanderson KE, Johnston RN, Liu SL: The genome of Salmonella enterica serovar gallinarum: distinct insertions/deletions and rare rearrangements. J Bacteriol 2005, 187:4720-4727.

23. Boyd EF, Wang FS, Whittam TS, Selander RK: Molecular genetic relationships of the salmonellae. Appl Environ Microbiol 1996, 62:804-808.
24. Didelot X, Achtman M, Parkhill J, Thomson NR, Falush D: A bimodal pattern of relatedness between the Salmonella Paratyphi A and Typhi genomes: convergence or divergence by homologous recombination? Genome Res 2007, 17:61-68.

25. Porwollik S, Frye J, Florea LD, Blackmer F, McClelland M: A nonredundant microarray of genes for two related bacteria. Nucleic Acids Res 2003, 31 : | 869-1876.

26. Mandel AD, Baron LS, Buckler CE: Role of Vi antigen in Salmonella paratyphi C infections. Proc Soc Exp Biol Med 1959, 100:653-656.

27. Nair S, Alokam S, Kothapalli S, Porwollik S, Proctor E, Choy C, McClelland M, Liu SL, Sanderson KE: Salmonella enterica serovar Typhi strains from which SPI7, a 134-kilobase island with genes for $\mathrm{Vi}$ exopolysaccharide and other functions, has been deleted. J Bacteriol 2004, | 86:32| 4-3223.

28. Bueno SM, Santiviago CA, Murillo AA, Fuentes JA, Trombert AN, Rodas PI, Youderian P, Mora GC: Precise excision of the large pathogenicity island, SPI7, in Salmonella enterica serovar Typhi. J Bacteriol 2004, 186:3202-3213.

29. Pickard D, Wain J, Baker S, Line A, Chohan S, Fookes M, Barron A Gaora PO, Chabalgoity JA, Thanky N, Scholes C, Thomson N, Quail $M$, Parkhill J, Dougan G: Composition, acquisition, and distribution of the Vi exopolysaccharide-encoding Salmonella enterica pathogenicity island SPI-7. J Bacteriol 2003, I 85:5055-5065.

30. Gauthier A, Turmel M, Lemieux C: A group I intron in the chloroplast large subunit rRNA gene of Chlamydomonas eugametos encodes a double-strand endonuclease that cleaves the homing site of this intron. Curr Genet 199I, 1 9:43-47.

31. Marshall P, Lemieux C: Cleavage pattern of the homing endonuclease encoded by the fifth intron in the chloroplast large subunit rRNA-encoding gene of Chlamydomonas eugametos. Gene 1991, 104:24I-245.

32. Marshall $P$, Lemieux $C$ : The I-Ceul endonuclease recognizes a sequence of 19 base pairs and preferentially cleaves the coding strand of the Chlamydomonas moewusii chloroplast large subunit rRNA gene. Nucleic Acids Res 1992, 20:640I-6407.

33. Marshall P, Davis TB, Lemieux C: The I-Ceul endonuclease: purification and potential role in the evolution of Chlamydomonas group I introns. Eur J Biochem 1994, 220:855-859

34. Kothapalli S, Nair S, Alokam S, Pang T, Khakhria R, Woodward D, Johnson W, Stocker BA, Sanderson KE, Liu SL: Diversity of Genome Structure in Salmonella enterica Serovar Typhi Populations. J Bacteriol 2005, 187:2638-2650.

35. Liu GR, Liu WQ, Johnston RN, Sanderson KE, Li SX, Liu SL: Genome plasticity and ori-ter rebalancing in Salmonella typhi. Molecular Biology and Evolution 2006, 23:365-371.

36. Liu SL, Hessel A, Sanderson KE: The Xbal-BInl-Ceul genomic cleavage map of Salmonella typhimurium LT2 determined by double digestion, end labelling, and pulsed-field gel electrophoresis. J Bacteriol 1993, 175:4104-4I20.

37. Liu SL, Sanderson KE: A physical map of the Salmonella typhimurium LT2 genome made by using $\mathbf{X b a l}$ analysis. J Bacteriol 1992, 174:1662-1672.

38. Kauffmann F: [Differential diagnosis and pathogenicity of Salmonella java and Salmonella paratyphi B.]. Z Hyg Infektionskr 1955, 141:546-550.

39. Le Minor L, Veron M, Popoff M: [A proposal for Salmonella nomenclature]. Ann Microbiol (Paris) 1982, 133:245-254.

40. Kidgell C, Reichard U, Wain J, Linz B, Torpdahl M, Dougan G, Achtman M: Salmonella typhi, the causative agent of typhoid fever, is approximately $\mathbf{5 0 , 0 0 0}$ years old. Infect Genet Evol 2002, 2:39-45.

4I. Roumagnac P, Weill FX, Dolecek C, Baker S, Brisse S, Chinh NT, Le TAH, Acosta CJ, Farrar J, Dougan G, Achtman M: Evolutionary History of Salmonella Typhi. Science 2006, 3 I 4: I30I-1 304

42. Neal BL, Brown PK, Reeves PR: Use of Salmonella phage P22 for transduction in Escherichia coli. J Bacteriol |993, 175:7| I5-7| I8. 